\title{
Miguel Ángel García, Un aire oneroso. Ideologías literarias de la modernidad en Es- paña (siglos XIX-XX), Madrid, Biblioteca Nueva, 2010, 354 pp.
}

Los tiempos que vivimos son confusos, como diría el maestro Pasolini en uno de los pasajes de «Una polémica en versos» de su célebre oda civil Las cenizas de Gramsci: «L'ora è confusa, e noi come perduti / la viviamo [...]». No en vano en Un aire oneroso. Ideologías literarias de la modernidad en España (siglo XIX-XX) se comienza recordando y citando otros célebres versos pasolinianos del homónimo poemetto: «Non è di maggio questa impura aria», haciendo alusión a ese aire pesado, gravoso, que flota a nuestro alrededor. La metáfora no puede ser más clara, y los versos nos ponen frente al problema: el aire que respiramos está corrompido o, atendiendo a la primera cita, vivimos como perdidos en un tiempo confuso, sin tener conciencia de lo que sucede mientras que el mundo sigue dando vueltas velozmente, acumulando cada vez más injusticias.

Esta suerte de confusión podría entenderse también como una narcosis que, continuando con la línea de este libro que reseñamos de Miguel Ángel García, profesor titular de Literatura Española de la Universidad de Granada, podría definirse mejor que nunca como «narcosis ideológica». El consumo en el que estamos envueltos sería sólo la capa más superficial y visible de esa trabazón que nos tiene ciegos, maniatados y mudos, que nos hace repetir como autómatas lo que el pensamiento dominante ha diseñado que digamos, veamos, repitamos y, en suma, seamos. Nos controlan hasta los deseos que pensamos más oscuros e individualizados (junto a nuestra pretendida individualidad), pues responden a concretas situaciones sentimentales históricas, y en eso consisten las corrientes ideológicas dominantes: no podemos salir de ellas.

Quizá lo único que se pueda hacer ante este aire que nos ha tocado respirar es tomar conciencia de su realidad corrosiva. Pero desde el pensamiento combativo de las últimas décadas lo que brilla por su ausencia precisamente es la toma de conciencia, ya que se ha generalizado un menefreguismo (término que se ha extendido en castellano también del italiano, de me ne frega, «no me importa») total, un caos desbordante. Ciertamente la falta de compromiso político es un síntoma de nuestros tiempos, que viven como natural el capitalismo avanzado, y cualquier otra alternativa de sistema económico, político, etc., se concibe como una alteración de ese orden natural -o dicho mejor, naturalizado - que se ha impuesto a cualquier otra concepción ideológica. La caída de la Unión Soviética no sólo supuso la derrota de una dictadura de facto que arruinó la revolución universal con las teorías estalinianas de la revolución dentro de la nación, frente a las internacionalistas de Trotsky. Supuso mucho más, porque la utopía se vio desmantelada en pocos años y cualquier tentativa de lucha por un mundo más justo y alternativo al capitalismo salvaje se considera como un despropósito, una suerte de intervención en el ciclo natural económico y social del hombre (porque parece ser y quieren convencernos de que lo natural del hombre es ser injusto). Dicen 
que el capitalismo es el sistema menos injusto de los que existen, extendiendo así la conocida frase aplicada a la democracia. Sin embargo muchos millones de personas todavía piensan en el planeta que no es cierto, y que lo que se está justificando es la miseria de la mayoría por el lujo y el fasto de unos pocos. Lo absolutamente nefasto de todo esto es que cualquier intento alternativo no tiene lenguaje para transmitir la transformación del mundo que pretende.

Dividido en diez capítulos y una introducción, Un aire oneroso. Ideologías literarias de la modernidad en España (siglo XIX-XX) es un recorrido sistemático y riguroso por la literatura desde Gustavo Adolfo Bécquer a Juan Ramón Jiménez, realizando en cada uno de ellos una escala profunda y sesuda sobre el estado de la cuestión de los autores o corrientes que desarrolla, tales como Rubén Darío, Campoamor, Ángel Ganivet, Valle-Inclán, el 98, el modernismo, la bohemia, Antonio Machado y Azorín, etc. La bibliografía es muy interesante, siempre atinada, y el lenguaje muy compacto, o mejor dicho, compactado, con escasez de comas y signos de puntuación (lo cual a veces hace las frases demasiado largas y hay que leerlas dos veces), evitando con eso pausas innecesarias. Esta propuesta de puntuación no es una casualidad, sino que forma parte de un determinado estado de escritura y pensamiento que merecería la pena calibrar más a fondo, pero que nosotros, ahora, en cualquier caso agradecemos enormemente. El profesor Miguel Ángel García da un repaso riguroso por los diferentes temas y capítulos recogidos, efectuando una puesta al día de algunos de los conceptos más peliagudos y a veces poco atractivos, de la literatura española, sin ambages ni anfibologías, criticando cuando tiene que criticar y señalando lo que le gusta cuando lo cree oportuno. En ese sentido estamos frente a un libro atrevido y que no se anda por las ramas. El marxismo como herramienta, como sistema total de pensamiento, no es aquí un mero utillaje teórico que nos acompaña en nuestros razonamientos, donde insertamos una noción más o menos osada o provocativa, sino una teoría general de las sociedades en movimiento aplicada a la literatura. Sin embargo durante el siglo XX, y sobre todo a finales, precisamente encuadrándose en la disolución del lenguaje de la izquierda y la caída de las utopías, los diferentes enfoques de la literatura estuvieron tan discutidos como la pretendida cientificidad de la Historia, abanderada por aquellos marxistas que luego acabaron cometiendo tantos errores para el pensamiento filosófico y político de izquierdas. A partir de estas premisas se plantean las problemáticas más interesantes e importantes por las que ha atravesado el «continente historia», hasta llegar a la desustancialización que supuso la posmodernidad con las consignas liberales de Fukuyama, aplicadas por Lyotard a la literatura: una historia que ha tenido que renunciar, como se sabe, a los grandes relatos, ya que vivimos una realidad fragmentada.

Pocos podemos añadir a un libro tan bien argumentado y presentado que no sean meros aspectos formales, ya que en lo tocante al fondo la escrupulosidad de Miguel Ángel García es realmente impresionante. Ya nos tenía acostumbrados con entregas como Vicente Aleixandre, la poesía y la historia (Comares, 2001), que fue su tesis doctoral; El Veintisiete en vanguardia (Pre-Textos, 2001), con el que consiguió el Primer Premio Internacional de Investigación Literaria Gerardo Diego; La poética de lo invisible en Juan 
Ramón Jiménez (Maillot Amarillo, 2002); o el muy reciente «Sin que la muerte al ojo estorbo sea». Nueva lectura crítica de Francisco de Aldana (Editora Regional de Extremadura, 2011). Sus obras son ciertamente para iniciados, no para esa inmensa minoría juanramoniana - que eran muchos más de lo que en primera instancia se supone, como bien demuestra el profesor García - sino para un exclusivísimo haz de estudiosos e iniciados que manejen ese lenguaje que además tendría como objetivo romper con esa jerga de la autenticidad (recordando a Adorno) que postula «una auténtica historia marxista de la literatura». Eso es imposible, claro está. Pero cualquier filólogo que haya seguido los pasos de Miguel Ángel García sabrá que nos encontramos ante uno de los estudiosos marxistas de la literatura más destacados del panorama actual, con unos planteamientos bien asentados y afirmados que ofrecen pocas dudas, sí disensiones o debate, pero desde una seriedad terminológica y metodológica muy bien articulada. No hay una sola lectura literaria de una obra, como tampoco hay una sola historia, sino diferentes relatos - narrativos, semióticos - que se van construyendo poco a poco en función de diversos intereses. Habrá que atender principalmente a ver quién los construye y por qué, de qué modo, cuáles son sus pros y sus contras, pero lamentablemente, igual que ya no aspiramos a construir un gran relato, como ya hemos dicho, hay que saber también cuáles son los fragmentos importantes que tenemos que recoger, que están ahí esperando ser recogidos, pues se trata de saber reconstruir una historia válida para cada momento, para cada circunstancia. No podemos seguir pensando como se pensaba hace medio siglo, y Miguel Ángel García actualiza el pensamiento marxista y lo aplica a la literatura. Sólo así podemos entender y emprender la transformación del mundo y del hombre.

Juan Carlos Abril 